Bentham OPen
CrossMark
Content list available at: www.benthamopen.com/TOCIEJ/
DOI: $10.2174 / 1874149501711010615$

RESEARCH ARTICLE

\title{
Light Transmitting Lightweight Concrete with Transparent Plastic Bar
}

\author{
Byoungil Kim*
}

School of Architecture, Seoul National University of Science \& Technology, 232 Gongneung-ro, Nowon-gu, Seoul 01811, Korea

\begin{abstract}
:
Introduction:

The ENV model proposed by TRIZ secured light transmission by replacing the existing costly transparent optical fibers with lowcost transparent materials with improved constructability, and improved the production method by changing the existing laborintensive method of laying thousands or tens of thousands of optical fibers into a labor-saving system capable of mass production, which involves the use of a large external multi-porous mold.
\end{abstract}

\section{Results and Conclusion:}

The application of plastic based bar against optical fiber showed that the light transmitting ability was almost equal as well as the convenience of making light transmitting concrete. Additionally, the difficulties coming from heavy weight of trial product for material preparation, transportation, and processing process were tried to solve by applying lightweight aggregate and light foaming agent while maintaining minimum compressive strength.

Keywords: Concrete, Light transmit, Transparent acrylic, Lightweight, Porous mold, Unit weight.

\section{INTRODUCTION}

Since recently, as the convergence between multi-disciplinary and dissimilar technologies has deepened, the social competition and the complexity of customer needs have increased, and the phenomenon where the boundaries between different disciplines, such as science and technology, engineering, humanities, and the social sciences, are destroyed has been highlighted. Now is the time to explore a framework for a new type of concrete technology through the fusion of engineering and science based on innovation (discontinuous innovation) beyond the advancement of the conventional concrete technologies in the past. The convergent thinking approach is the process of deriving new ideas based on stereotyped knowledge in the existing passive learning, whereas the divergent thinking approach is the process of addressing the inhibition of creative thinking by stereotyped knowledge and thus of making new ideas and coming up with new creations through new thinking without boundaries, contrary to the network of knowledge. Creating new values through the existing convergent thinking approach is meaningless in the current fast-changing science and engineering world, and there is a need to create values through a new innovation process in the field of engineering by sharing different ideas and values, away from the stereotyped framework based on the existing knowledge [1].

A look at the recent trends in the development of concrete technologies would reveal that due to the improved durability of buildings and the increased domestic and international interest in eco-friendliness, the construction industry has faced changes in the concrete technology that meets the multi-functions beyond the existing scope, which consists of high-durability concrete, concrete suitable for a special environment, and ultra-lightweight concrete [2 - 6].

\footnotetext{
* Address correspondence to this author at the School of Architecture, Seoul National University of Science \& Technology, 232 Gongneung-ro, Nowon-gu, Seoul 01811, Korea; Tel: +82-2-970-6512; E-mail: bikim@seoultech.ac.kr
} 
Given the current environmental problems and the increase in the demand for functionally diversified concrete, the demand for such is expected to continuously increase.

The light-transmitting, transparent concrete invented by Hungarian architect Aron Losonczi in 2001 was developed through concrete pouring and curing steps after placing optical fiber evenly on the concrete surface, along with cement, water, and stone powder, in a straight line, with a $4-10 \%$ weight ratio. With regard to the basic principle of the lighttransmitting concrete, the optical fiber used in the field of electronics and telecommunications was applied to the concrete [7]. Unlike general materials, optical fiber has the characteristic of allowing light to completely pass through its surface, without any loss, through the total reflection of light, regardless of the light direction. Through this characteristic, the incorporation of tens of thousands of optical fiber in concrete can enable the latter to exhibit the effect of allowing the concrete to pass through the silhouette of an object due to the external light transmitted through the concrete. Optical fiber consists of a core and a cladding, where the core portion is responsible for the transmission of light and the cladding is configured to play a role in preventing the loss of light in the process of the total reflection of light $[7-10]$.

The light-transmitting, transparent concrete using optical fiber is mixed with a ratio of about $4-10 \%$ of the total concrete volume, and the optical fiber characterized by total reflection helps ensure light transmission without loss of light despite the configuration of of walls with several meters in size. In Europe, a variety of products for interior and exterior building materials are currently being developed. For the physical properties, the compressive strength is 50 $\mathrm{MPa}$, the standard block size is $600 \times 300 \mathrm{~mm}$, the thickness is $25-500 \mathrm{~mm}$, and the density is $2100-2400 \mathrm{~kg} / \mathrm{m}^{3}$ [11].

Light-transmitting, transparent concrete has been widely used as indoor and outdoor building materials in foreign countries, but it has limitations in marketability due to high price optical fibers(roughly 20-50\$ per meter). To overcome the drawbacks of light-transmitting, transparent concrete and to boost its spread to construction market, a manufacturing technique that ensures superior constructability and that is different from the existing manufacturing techniques should be developed, and transparent materials that have light-transmitting properties and that are highly economical have to be secured. In the case of the optical fiber that is generally used in the production of light-transmitting concrete, the smaller the diameter is, the lower the price. There are problems, however, with regard to how to effectively place numerous optical fibers inside the concrete accounting for $4-10 \%$ of the total concrete volume. The production processes to secure light transmission by arranging tens of thousands of optical fibers one by one result in the lack of economic efficiency of expensive optical fiber as well as a rise in the labor cost due to the intensive labor force required in the production process [11]. In addition, as the optical fiber material itself has great flexure, a huge amount of time is required even just to produce light-transmitting concrete with the size of a small brick.

This study sought to secure constructability and economic efficiency by dramatically replacing it with transparent materials that ensure superior economic efficiency, and to actively implement practicalization at the construction site not only by diversifying the types of products to be developed in the future but also by introducing changes in the light transmission process through the differentiation of light sources. In addition, this study attempted to develop a futureoriented concrete technology for the future living environment by evolving the existing inorganic and non-emotional concrete image into emotion-friendly concrete, with focus on the residents, through technology development for a newconcept light-transmitting concrete that takes artistry into account.

\section{NEW APPROACH FOR LIGHT TRANSMITTING CONCRETE}

\subsection{Overview}

This study applied the problem-solving method proposed by TRIZ (theory of solving inventive problem) to resolve the problems of the existing light-transmitting, transparent concrete: costly materials and low constructability [1]. For the first problem, this study substituted existing materials with low-cost transparent materials, and improved the old labor-intensive production process, which involves laying thousands or tens of thousands of optical fibers into concrete, by changing it into a labor-saving production process capable of mass production. To find a creative solution by reducing the gap between the current and desired targets, this study applied ENV (element, name of feature, value of feature), one of the problem-solving models proposed by TRIZ. The ENV model consists of the elements, name of feature, value of feature (the current target, and the desired target) as shown in Table 1. First, the elements were divided into the material property, material type, manufacturing method and economy. The names of feature were light transparent, working hours, arrangement and production method. The existing costly optical fiber transparent material can be replaced with low-cost transparent and straight type of materials such as plastic fiber, glass, or acrylic. The 
existing connecting materials were replaced with an external multi-porous mold to improve the construction process from a labor-intensive process to a labor-saving one. The production system was also improved into a system capable of mass production, where an integral production system produces a long shape with an even thickness, which can be divided into the desired sizes.

Table 1. ENV model from TRIZ.

\begin{tabular}{|c|c|c|c|}
\hline \multirow{2}{*}{ Element } & \multirow{2}{*}{ Name of feature } & \multicolumn{2}{|c|}{ Value of feature } \\
\cline { 2 - 4 } & & Current object & Desired object \\
\hline Material property & Light transparent & Curved type & Sransparent plastic \\
\hline Material type & Construction efficiency & Inside & Outside \\
\hline Manufacturing approach & Arrangement & One-piece & Cutting type \\
\hline Economy & Production method & \\
\hline
\end{tabular}

\subsection{Materials Used}

For the experiment, the ordinary Portland cement (type 1) was used. The physical properties of the cement satisfy the KS L 5201 specifications. The specific gravity of the fine aggregates is $2.58 \mathrm{~g} / \mathrm{cm}^{3}$, the absorption rate is $1.5 \%$. Coarse aggregates were not used to fill the inside of the transparent materials due to construction issues. $10 \mathrm{~mm}$ steel fibers were applied to $0.5 \%$ of the overall volume. Acrylic pipes and rods were applied as shown in Fig. (1) to secure transparency for the cement concrete block matrix and to greatly improve the constructability using their straight shapes. The existing optical fiber offers superb light transmission but involves a serious amount of labor and cost increase for arranging thousands or tens of thousands of bent fibers in one direction within the cement or concrete matrix. Light-transmitting and straight plastic materials, however, can be arranged in a matrix with a smaller workforce in a shorter time. The diameter of the materials that were used varied from 3 to $10 \mathrm{~mm}$, and the types that were applied included hollow pipes.

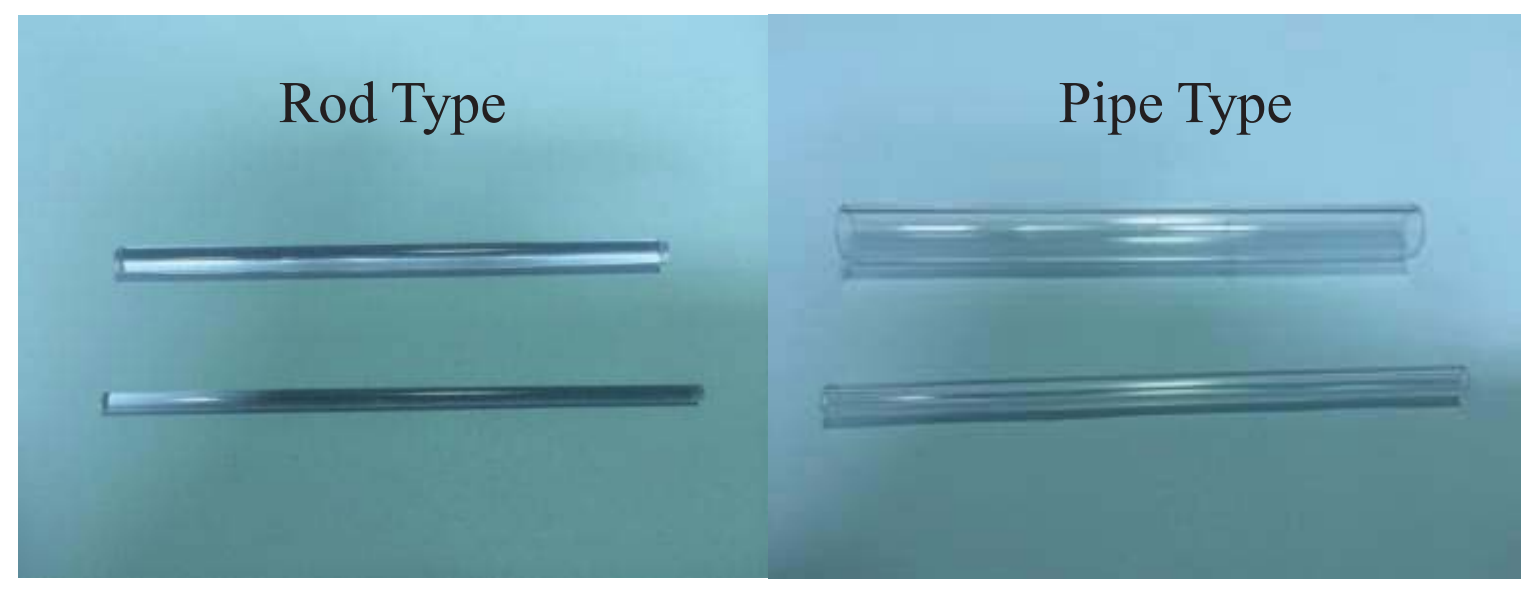

Fig. (1). Transparent acrylic rods \& pipes.

\subsection{Experiment Design}

In the experiment, the design of the mix proportion was done by excluding coarse aggregates to prevent the fiber balling phenomenon and problems in construction due to the narrow gap of the transparent materials in the process of pouring high-fluidity concrete inside the block. The concrete mix design is summarized in the Table 2 below. The materials that are used are made by mixing cement, ground granulated blast slag (GGBS), fine aggregates (FA), steel fiber $(10 \mathrm{~mm})$, super-plasticizer and transparent materials (acrylic). With a mix of 38\% W/C, 3\% air, $0.5 \%$ steel fiber, and up to $2 \%$ super-plasticizer (SP), high-fluidity concrete was produced and poured.

Table 2. Mix proportions $\left(\mathrm{kg} / \mathrm{m}^{3}\right)$.

\begin{tabular}{|c|c|c|c|c|c|c|}
\hline Mix type & Water & Cement & GGBS & FA & Fiber & Acrylic type \\
\hline AR_3 & 200 & 550 & 50 & 839 & 36 & Rod $(3 \mathrm{~mm})$ \\
\hline AR_5 & 200 & 550 & 50 & 839 & 36 & Rod $(5 \mathrm{~mm})$ \\
\hline AR_10 & 200 & 550 & 50 & 839 & 36 & Rod $(10 \mathrm{~mm})$ \\
\hline
\end{tabular}


(Table $\square$ ) contd....

(Table $\square$ contd.....
\begin{tabular}{|c|c|c|c|c|c|c|}
\hline Mix type & Water & Cement & GGBS & FA & Fiber & Acrylic type \\
\hline AP_5 & 200 & 550 & 50 & 839 & 36 & Pipe $(5 \mathrm{~mm})$ \\
\hline AP_10 & 200 & 550 & 50 & 839 & 36 & Pipe $(10 \mathrm{~mm})$ \\
\hline Mixed ARP & 200 & 550 & 50 & 839 & 36 & Mixed $(3,5,10 \mathrm{~mm})$ \\
\hline
\end{tabular}

\subsection{Production Process}

The production process of light-transmitting concrete block is shown in the following Fig. (2). First, low-cost acrylic rod or pipe for securing transparency is prepared, with $110 \mathrm{~mm}$ lengths. The outside of the mold is drilled to make various-sized holes $(3,5$, and $10 \mathrm{~mm})$ in stainless steel. The distance between the holes is the same as the size of the hole. The size and number of holes are important factors that determine the constructability and economic efficiency of the project, and the degree of light transmission is determined depending on the number of holes. The advantages of the external-type mold are that it can be reused as it is prefabricated by the outside partner and requires no intricate operations for the arrangement of the optical fibers in a line after adjusting each fiber and connecting it to the holes. In addition, there is no need to widen the surface area by heating the end of the optical fiber, as in the case of optical fiber [7]. In the prepared mold as shown in Fig. (3), cement, water, fine aggregates, steel fiber and super-plasticizer were mixed with high fluidity (about $70 \mathrm{~cm}$ as a result of the flow test) and were placed inside the mold, into which a transparent material was inserted, and then the mold was hammered lightly with a rubber mallet so that the mold would be filled with the concrete. The prototype was completed by cutting it with the desired thickness after proceeding with underwater curing for 28 days by removing the mold after room curing for at least 24 hours in the mixing process.

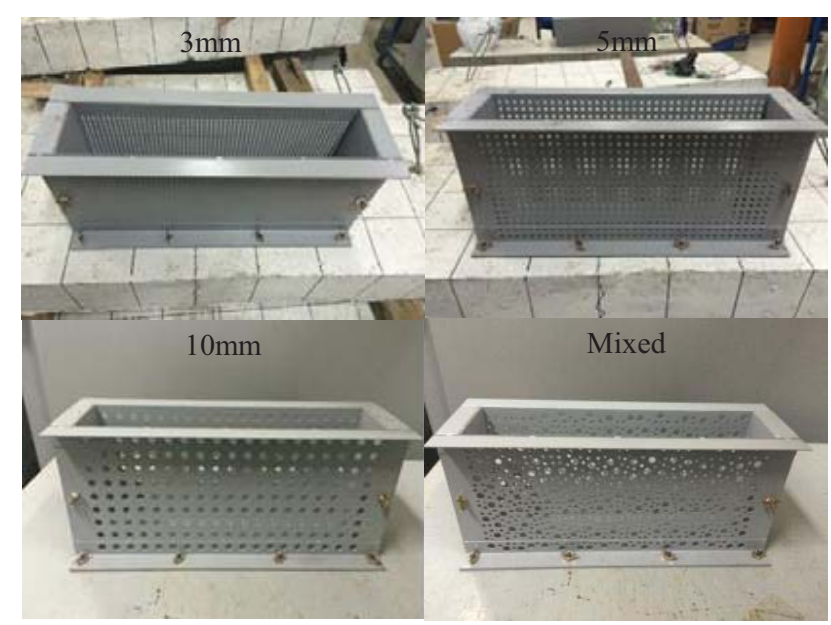

Fig. (2). Various types of molds $(3,5,10 \mathrm{~mm})$.

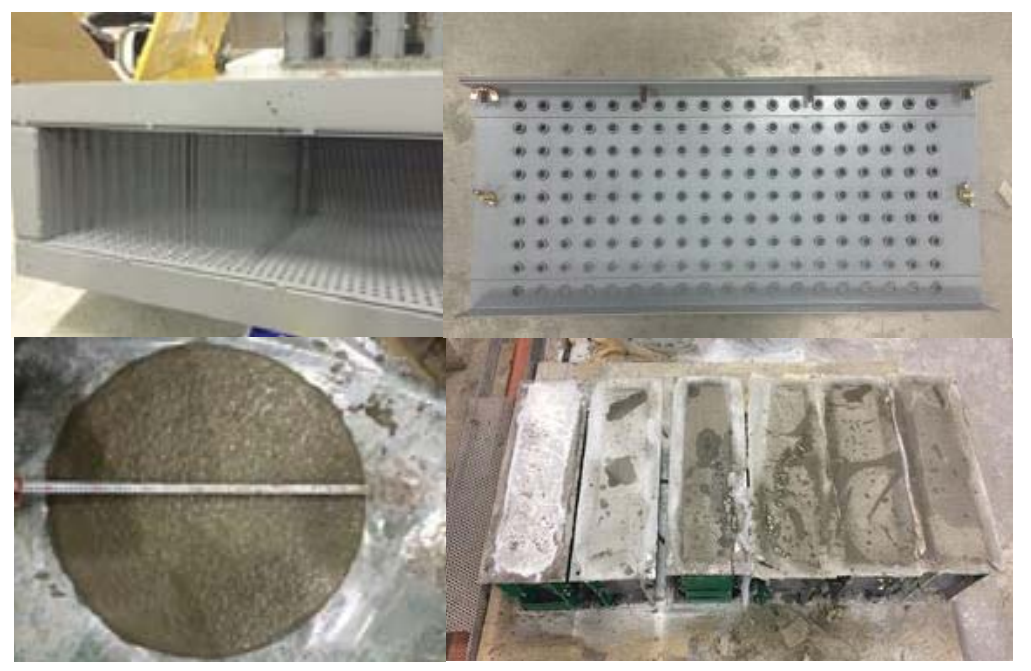

Fig. (3). Production process (acrylic rod/pipe with high flow able concrete). 


\subsection{Results}

The results of the observation of the changes in the color of luminous concrete due to the emission of light are shown in Fig. (4). The space was filled using the concrete after the arrangement of the transparent materials in one direction. The transmission of light was found to be superior in all the materials and diameters. In particular, the smaller the diameter of the transparent material is, the more excellent the permeation degree of the object caused by the transmission of light, due to the dense array of small light sources. In addition, it was found that although as the diameter becomes larger a huge amount of light can be transmitted due to the greater light source, the accuracy of the object tends to be lower. Fig. (5) shows the transmission effects caused by the external object. When held up before the light prior to processing the concrete, the shape of the person was clearly shown behind the concrete block, which indicates that the object blocked the external light, thereby preventing the transmission of light, and the outline of the object appeared. Fig. (5) also shows that the results of the observation of the transmission of light after the concrete were cut into $50 \mathrm{~mm}$ pieces using a concrete saw cutting machine. After processing, the light transmission effect was further enhanced, and the effect of seeing through the external object was significantly improved as well.

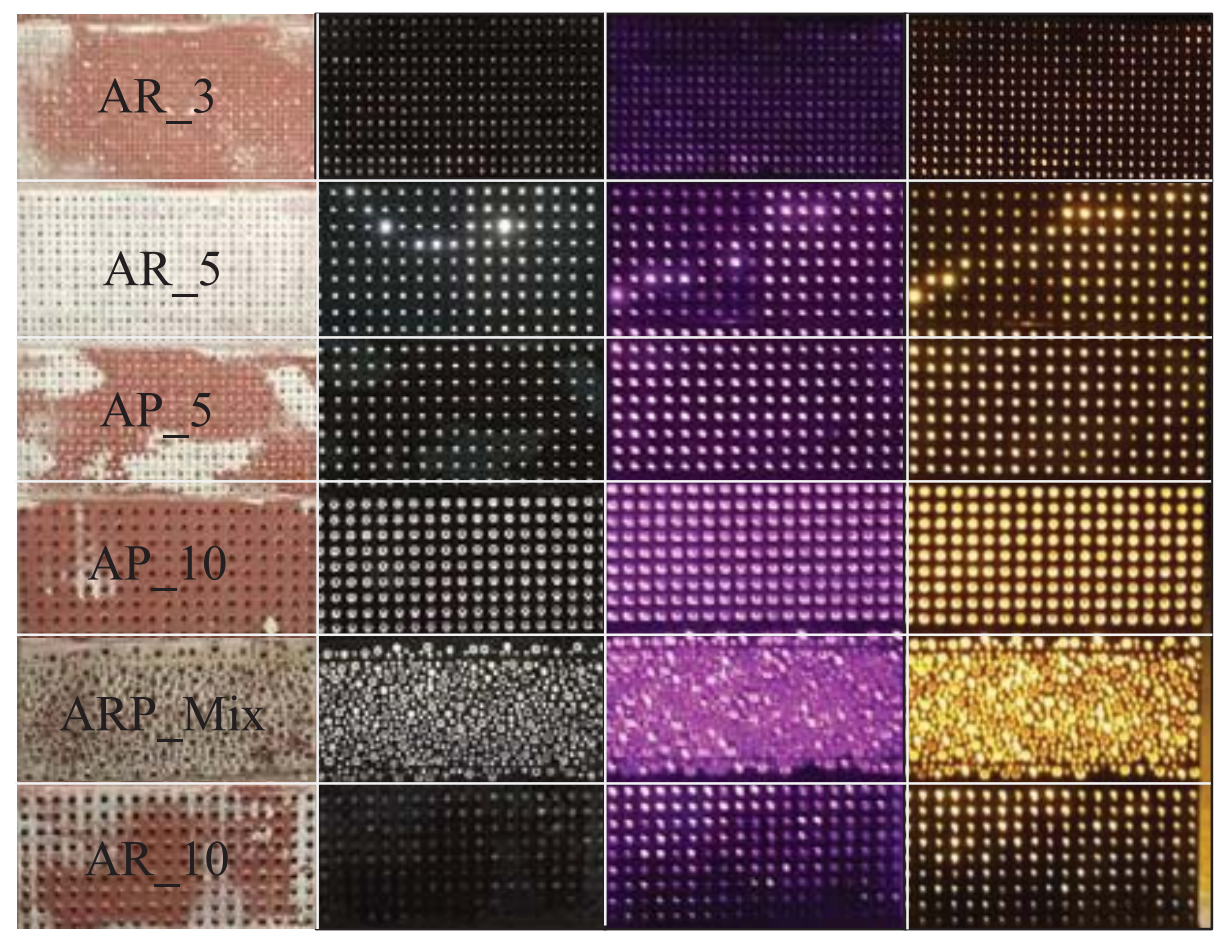

Fig. (4). Luminous color images from different light sources.

\subsection{Problem}

As concrete structures become larger and higher, the heavy dead load of the structure becomes one of the defects. Accordingly, there is a need to reduce the weight of the structure while maintaining the mechanical performance to decrease the dead load and to improve the constructability when applied to the structure. The light-transmitting concrete block with enhanced constructability and economic efficiency was produced by utilizing materials that transmit light, but critical problems were found in the process of transmitting light using the prototype. It is expected that if ordinary concrete materials are used, difficulties will arise in the materials preparation, transportation, and processing processes. In particular, as the labor force and time required after the production of large concrete locks is expected to increase in the transporting and processing processes, these problems need to be solved before the field application in the future. To solve the problems that occur in the relatively complicated manufacturing and processing steps, and to secure more practical technologies, this study sought to further investigate methods of ensuring the mass production and ease of production through lightweight concrete placement by applying lightweight aggregates and a lightweight foaming agent in ordinary concrete with a large unit weight [12]. 


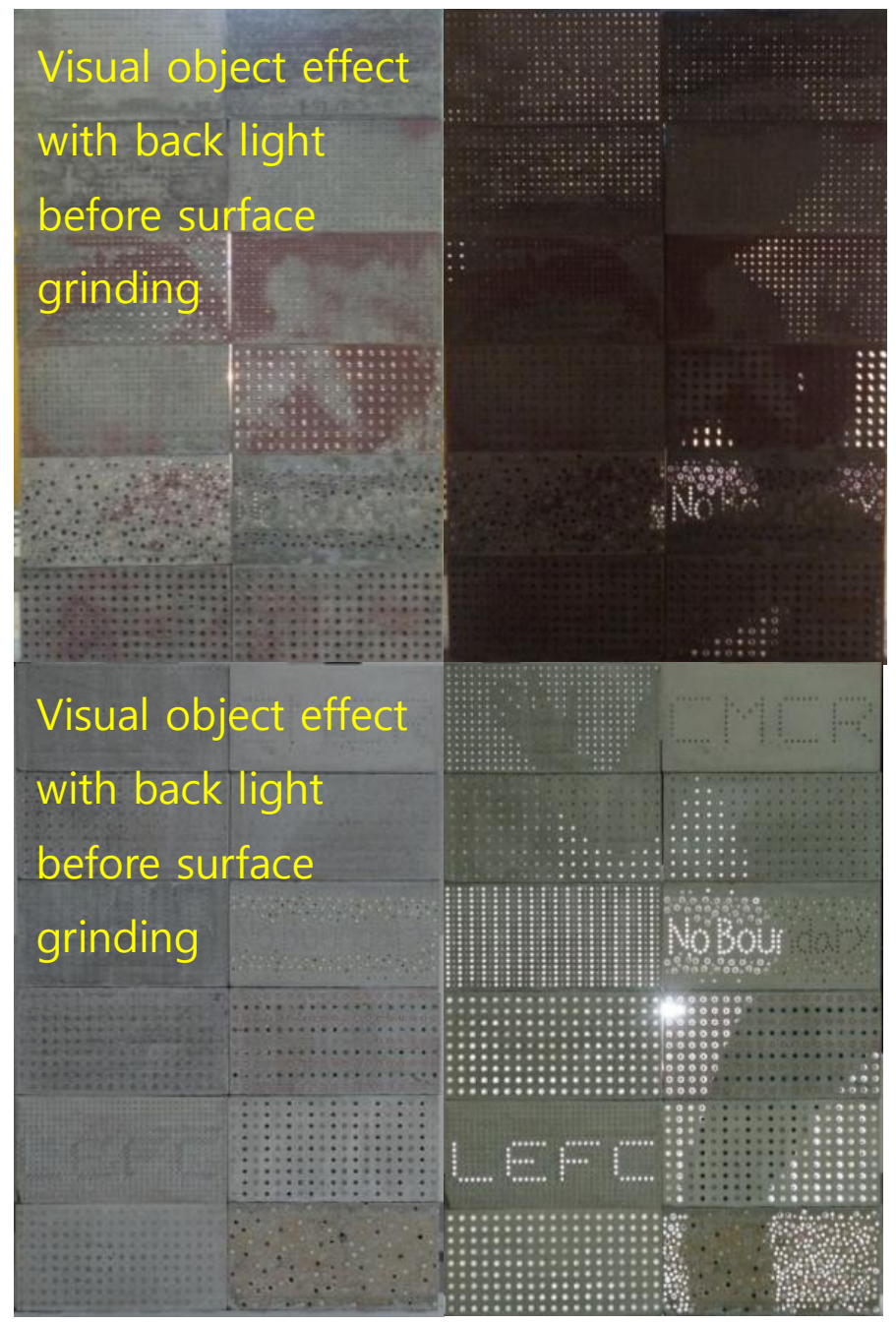

Fig. (5). Visual object effect before and after surface treatment.

\section{LIGHT TRANSMITTING LIGHTWEIGHT CONCRETE WITH LIGHTWEIGHT AGGREGATE}

\subsection{Materials Used}

In the experiment, ordinary Portland cement (type 1) as before mentioned was used. The physical properties of the used cement meet the KS L 5201 specifications. The specific gravity of the fine aggregates is $2.58 \mathrm{~g} / \mathrm{cm}^{3}$, the absorption rate is $1.5 \%$. The steel fiber with a $10 \mathrm{~mm}$ length was used to enhance the crack resistance in the transverse direction by applying $0.5 \%$ of the total volume. Fly ash artificial lightweight aggregates were purchased from S Company and were used in the experiment. The maximum aggregate size was $10 \mathrm{~mm}$, and the physical properties of the aggregates that were used in the experiment are summarized in Table 3. To secure transparency in the matrix of the cement-concrete block, acrylic pipes and rods were also applied.

Table 3. Material property of artificial lightweight aggregate.

\begin{tabular}{|c|c|c|c|c|c|c|}
\hline Aggregate & $\begin{array}{c}\text { Unit weight } \\
\left(\mathbf{k g} / \mathbf{m}^{\mathbf{3}}\right)\end{array}$ & Specific gravity & $\begin{array}{c}\text { Porosity } \\
\mathbf{( \% )}\end{array}$ & $\begin{array}{c}\text { Absorption } \\
\mathbf{( \% )}\end{array}$ & $\begin{array}{c}\text { Percentage of solid volume } \\
\text { (\%) }\end{array}$ & Fineness modulus \\
\hline Fly ash artificial lightweight aggregates & 840 & 1.35 & 35 & 24.3 & 64 & 6.45 \\
\hline
\end{tabular}

\subsection{Experiment Design}

In the experiment, the design of the mix proportion was done by limiting the maximum dimension of the coarse aggregates to $10 \mathrm{~mm}$ to prevent problems in construction due to the narrow gap of the transparent materials in the process of pouring high-fluidity, artificial, light weight aggregate concrete inside the block. The concrete mix design is summarized in the following Table 4. The materials that were used are made by mixing cement, fine aggregates, 
artificial lightweight aggregates (LWA), steel fiber $(10 \mathrm{~mm})$, super-plasticizer, and transparent materials (acrylic rods and pipes with $5 \mathrm{~mm}$ size). With a mix of $33 \% \mathrm{~W} / \mathrm{B}, 4.5 \%$ air, $0.5 \%$ steel fiber, and up to $2 \%$ super-plasticizer (SP), fluidity lightweight aggregate concrete was produced for placement.

Table 4. Mix proportions with artificial lightweight aggregate $\left(\mathrm{kg} / \mathrm{m}^{3}\right)$.

\begin{tabular}{|c|c|c|c|c|c|c|}
\hline Mix type & Water & Cement & FA & CA & Fiber & Acrylic type \\
\hline AR_LWA & 200 & 550 & 839 & 715 & 36 & Rod $(5 \mathrm{~mm})$ \\
\hline AP_LWA & 200 & 550 & 839 & 715 & 36 & Pipe $(5 \mathrm{~mm})$ \\
\hline
\end{tabular}

\subsection{Mixture and Production}

The production process of light-transmitting concrete block is shown in the following Fig. (6). First, low-cost acrylic rods and pipes for securing transparency are prepared. In the artificial lightweight aggregate concrete, a mold (size-200 $\times 300 \times 500 \mathrm{~mm}$, distance between holes-20mm) made of stainless steel is prepared to fabricate several specimens with different thicknesses using a cutter. The outer side of the mold is fixed with the use of strong adhesive tape after connecting rods or pipes made of various materials to prevent the rod from shaking. The advantage of the external-type mold is that it can be reused several times as it is prefabricated by the outside partner.

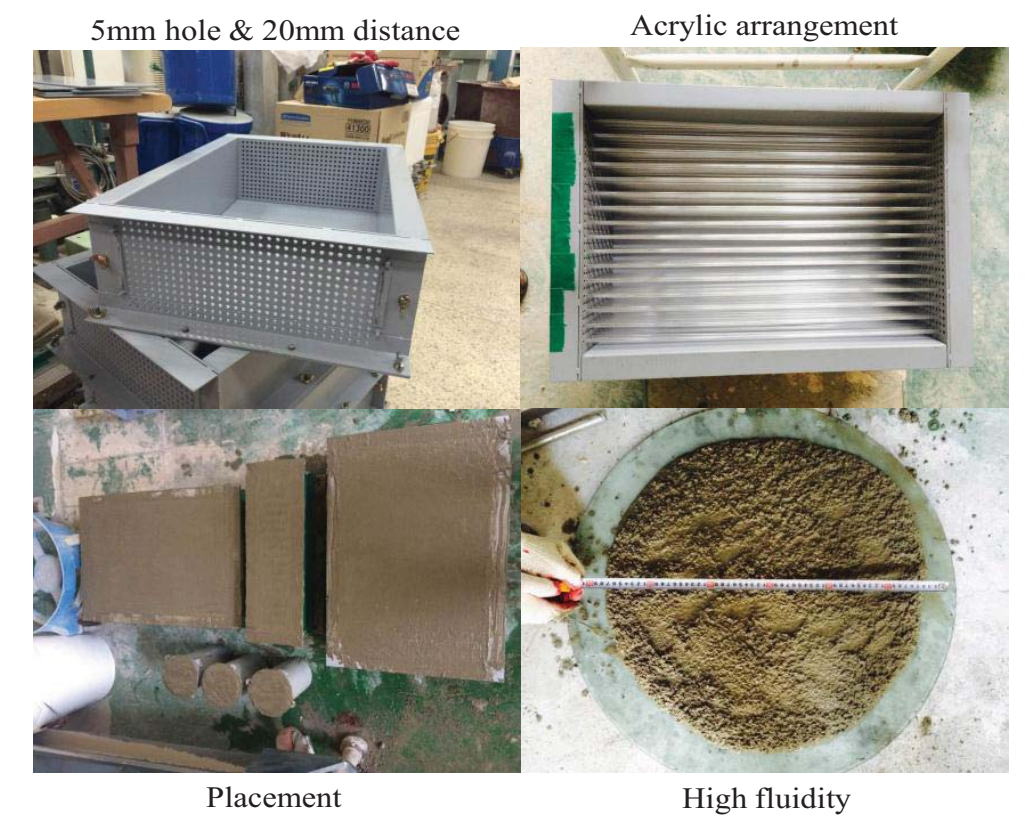

Fig. (6). Production process (acrylic rod/pipe with high flow able concrete) for application of fly ash artificial lightweight aggregate.

In the mold with which acrylic rods and pipes are connected, cement, water, fine aggregates, artificial lightweight aggregates, steel fiber, and super-plasticizer are mixed with high fluidity (about $60 \mathrm{~cm}$ as a result of the flow test) and are placed inside the mold into which a transparent material is inserted, and then the mold is hammered lightly with a rubber mallet so that the mold would be filled with the concrete. The prototype was completed by cutting it with the desired thickness after proceeding with underwater curing for 28 days by removing the mold after room curing for at least 24 hours in the mixing process.

\section{LIGHT TRANSMITTING LIGHTWEIGHT CONCRETE WITH LIGHTWEIGHT FOAMING AGENT}

\subsection{Materials Used}

As a foaming agent, Alcohol Ethoxy Sulfate (AES) consisting of anionic surfactants widely used in South Korea was applied (Table 5). To secure transparency in the matrix of the cement-concrete block, acrylic pipes and rods were applied. In the prototype that was produced earlier, transparent materials that ensure higher applicability in the field were applied considering the constructability and economic efficiency. Acrylic rod and pipe with $5 \mathrm{~mm}$ size were applied. 
Table 5. Material property of foaming agent.

\begin{tabular}{|c|c|c|c|c|c|}
\hline Type & $\begin{array}{c}\text { Active matter } \\
(\mathbf{\%})\end{array}$ & $\begin{array}{c}\text { Free oil } \\
(\mathbf{\%})\end{array}$ & $\mathbf{N a}_{\mathbf{2}} \mathbf{S O}_{\mathbf{4}}$ & $\begin{array}{c}\text { Klett color } \\
(\mathbf{5 \%} \mathbf{A M})\end{array}$ & $\begin{array}{c}\mathbf{p H} \\
(\mathbf{N e a t}, \mathbf{2 5}\end{array}$ \\
\hline Alcohol ethoxy sulfate (AES) & 28.15 & 0.31 & 5.00 & 0.16 & 7.50 \\
\hline
\end{tabular}

\subsection{Experiment Design}

The lightweight foamed concrete mixture design is summarized in Table $\mathbf{6}$. The level of volume equal to the amount of the powder was applied to the foaming agent. The materials that were used were made by mixing cement, fine aggregates, a foaming agent, and transparent materials (acrylic rods and pipes). The foaming agent was applied to the concrete using a pre-foaming method. The foam was made using a foaming machine after pouring foaming agent diluting fluid with the use of a method for extruding air. The status of the foam (spherical type) was checked prior to being put into the concrete sludge.

Table 6. Mix proportions with foaming agent $\left(\mathrm{kg} / \mathrm{m}^{3}\right)$.

\begin{tabular}{|c|c|c|c|c|c|}
\hline Mix type & Water & Cement & Form & SP (\%) & Acrylic type \\
\hline AR_FA & 15.4 & 11.9 & 23.1 & 0.04 & Rod $(5 \mathrm{~mm})$ \\
\hline AP_FA & 15.4 & 11.9 & 23.1 & 0.04 & Pipe $(5 \mathrm{~mm})$ \\
\hline
\end{tabular}

\subsection{Mixture Production}

The production process of lightweight foamed concrete block following almost same procedure is shown in the following Fig. (7). In the mold with which acrylic rods and pipes are connected, high-fluidity foamed concrete as shown in Fig. (7) is placed inside the mold into which a transparent material is inserted, and then the mold is lightly hammered with a rubber mallet so that the mold would be filled with the concrete. The prototype was completed by cutting it with same procedure mentioned above lightweight aggregate applied specimen.

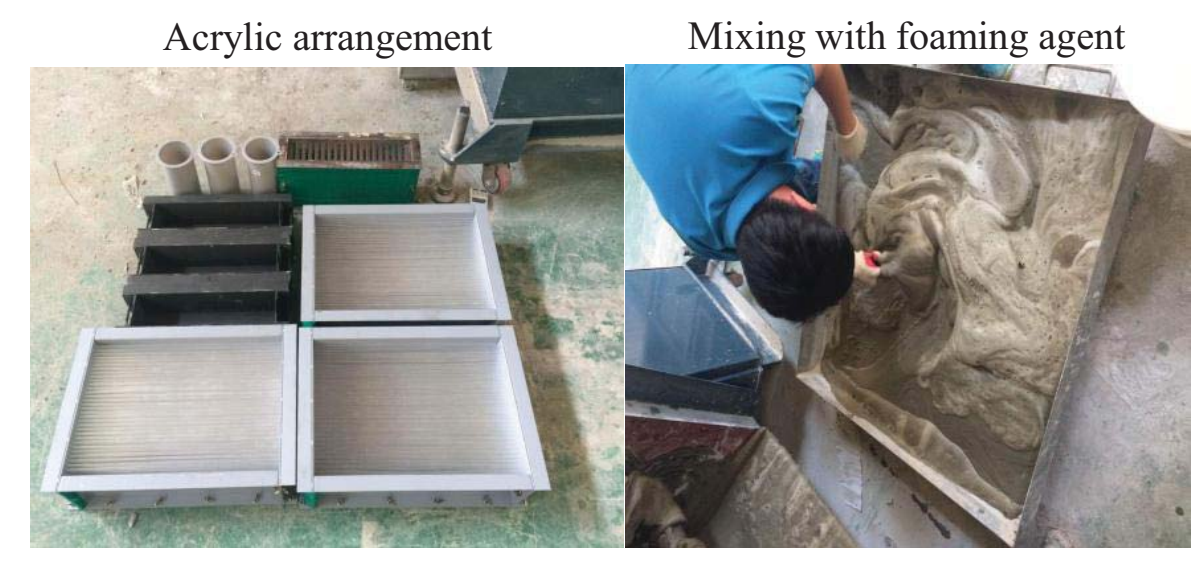

Fig. (7). Process (acrylic rod/pipe with high flow able concrete) for application of AES lightweight foaming agent.

\section{EXPERIMENTAL RESULTS}

\subsection{Unit Weight}

The results of the comparison of the unit weights of the fresh-concrete statuses in Fig. (8) revealed that the unit weights of the lightweight aggregates and of the lightweight foamed concrete were much lower than that of ordinary concrete, and especially, the unit weight of lightweight foamed concrete was about half that of lightweight aggregate concrete. This suggests that due to the effects of the foaming agent and lightweight aggregates, a lighter unit weight contributes to easier production in the commercialization phase, and to superior constructability in the field. 


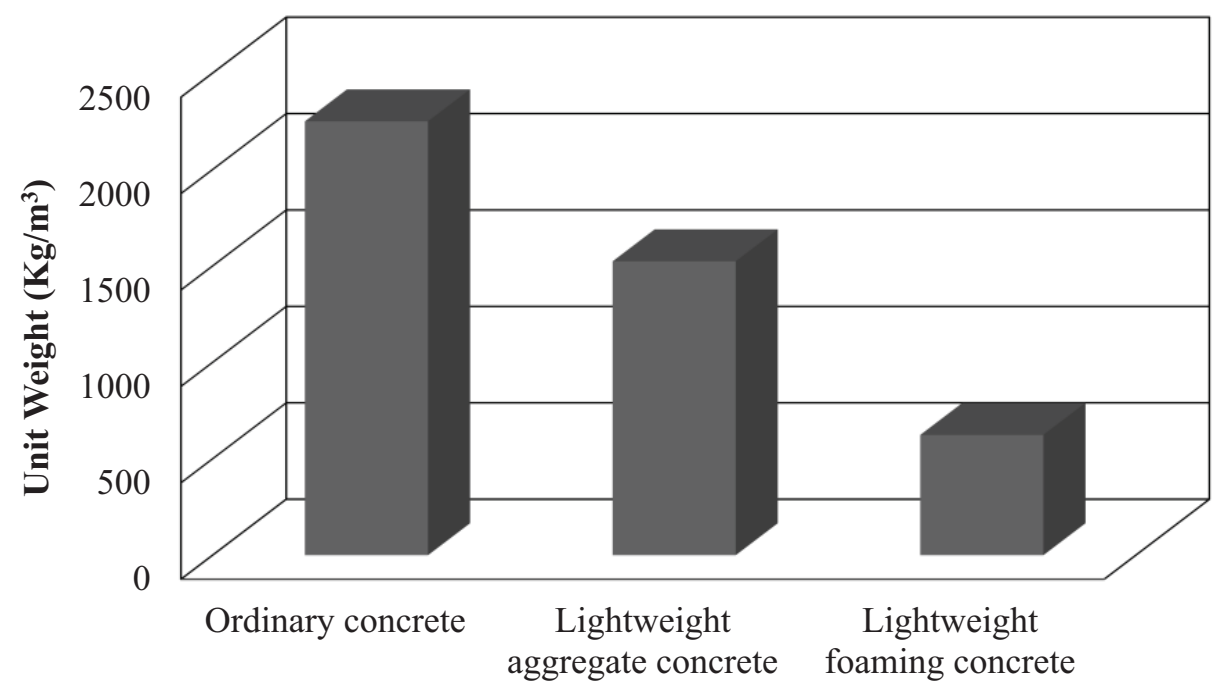

Fig. (8). Weight comparison.

\subsection{Compressive Strength}

The compressive strength test results are summarized in the following Fig. (9). In the case of the lightweight aggregate concrete specimen, the distribution statuses of the aggregates and of steel fiber were confirmed after surface grinding, and the compressive strength was found to be $18.2 \mathrm{MPa}$, which is significantly lower than that of the specimen to which ordinary concrete was applied. The formation of numerous foams was found on the surface of the lightweight foamed concrete specimen, and the compressive strength was 4.6 MPa.

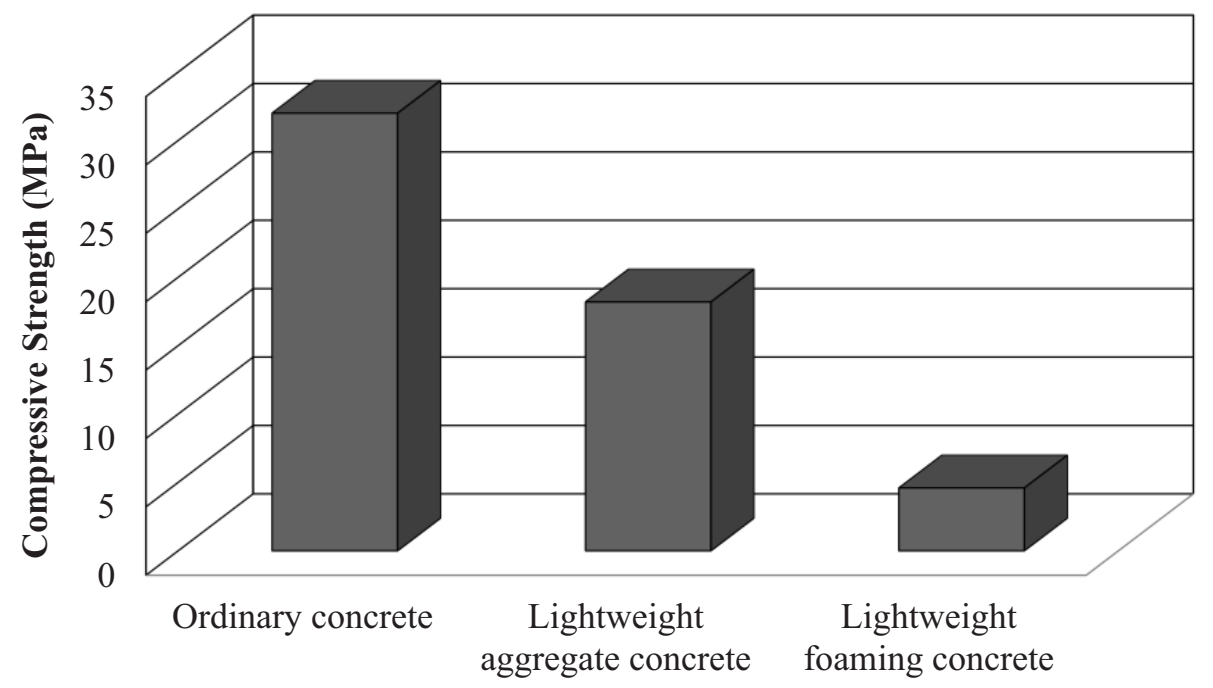

Fig. (9). Strength comparison.

\subsection{Effects of the Light-Transmitting Lightweight Concrete}

The following Fig. (10) shows the transmission of light by cutting the $300 \times 500 \mathrm{~mm}$ specimen into a 50 -mm-thick piece after applying lightweight aggregates and foaming agent. The light transmission is clearly identified, as shown in the figure. There are any no differences between products except for materials used for reducing unit weight. The effect of light transmission is the same due to the same transparent materials used. In particular, as the diameter of the transparent rod or pipe becomes larger, the surface area of the entire concrete becomes greater, and the light transmission becomes higher. As the light source becomes larger, however, the representation of the object may not be as detailed as it should be. 


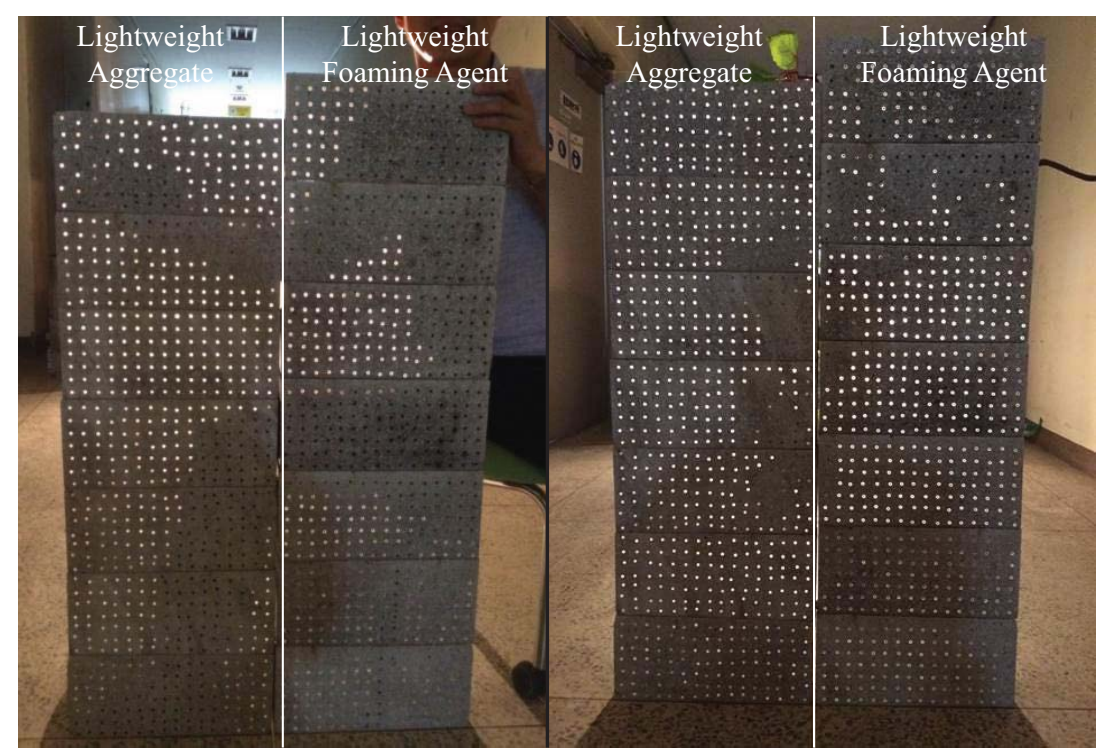

Fig. (10). Object effect for lightweight aggregate and foaming concretes (person and leaf).

\subsection{Various Visual Effects of the Light Emotion Friendly Concrete}

The light emotion friendly concrete (LEFC) named by author can have a variety of aesthetic effects by being applied to inorganic concrete with the use of transparent plastic-based rods or pipes. LEFC is the name of the technology applied in this study, an abbreviated form of "light-transmitting, emotion-friendly concrete." In addition, it is possible to deliver a strong message by mixing transparent materials of various sizes and representing letters as shown in Fig. (11).

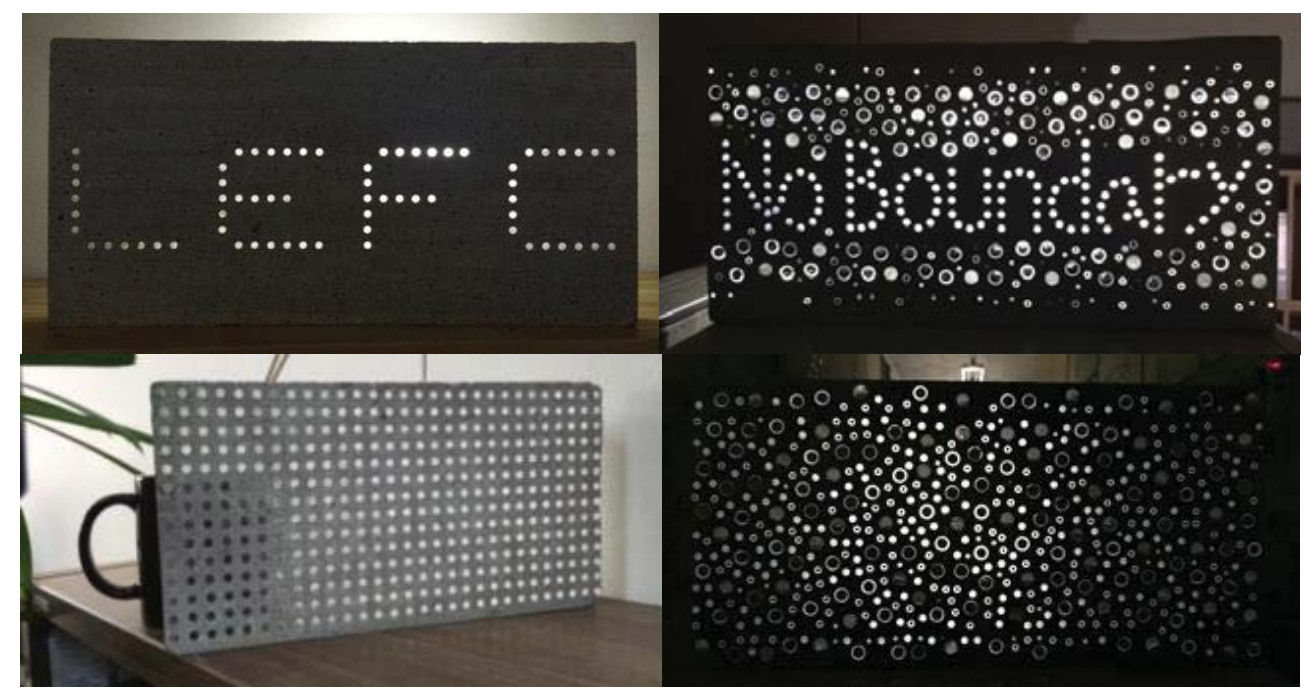

Fig. (11). Effect (advertisement having strong message).

\section{CONCLUSION}

The most important consideration in this study was the price of the light-transmitting concrete made of the existing optical fiber. As it currently sells for almost two thousands dollar per square meter of concrete block containing $4 \%$ optical fiber volume with application of $1 \mathrm{~mm}$ diameter of optical fiber (20 dollars per meter), its widespread application in industry is impossible at present to around globe. In this regard, this study attempted to significantly reduce the amount of fiber required in the production of the concrete by converting expensive optical fiber into inexpensive plastic-based rod ( 2 dollars per meter), and thus to produce light-transmitting concrete that ensures economic efficiency(20 dollars per square meter) 
To summarize, this study applied the ENV model proposed by TRIZ, and thereby secured light transmission by replacing the existing costly transparent optical fibers with low-cost transparent materials with improved constructability, and improved the production method by changing the existing labor-intensive method of laying thousands or tens of thousands of optical fibers into a labor-saving system capable of mass production, which involves the use of a large external multi-porous mold. Additionally, the difficulties coming from heavy weight of trial product for material preparation, transportation, and processing process were tried to solve by applying lightweight aggregate and light foaming agent with maintaining minimum compressive strength.

\section{LIST OF ABBREVIATIONS}

The following abbreviations are used in this manuscript:

$\begin{array}{lll}\text { KS } & = & \text { Korean industrial Standards } \\ \text { ENV } & = & \text { Element, Name of Feature, Value of Feature } \\ \text { TRIZ } & = & \text { Theory of Solving Inventive Problem } \\ \text { GGBS } & = & \text { Fround Granulated Blast Slag } \\ \text { FA } & = & \text { Light Weight Aggregate } \\ \text { LWA } & = & \text { Acrylic Rod } \\ \text { AR } & = & \text { Acrylic Pipe } \\ \text { AP } & = & \text { Alcohol Ethoxy Sulfate } \\ \text { AES } & = & \text { Light Emotion Friendly Concrete } \\ \text { LEFC } & \end{array}$

\section{AUTHOR'S CONTRIBUTIONS}

Byoungil Kim conceived, designed the experiments and analyzed the data as well as writing the paper.

\section{CONSENT FOR PUBLICATION}

Not applicable.

\section{CONFLICT OF INTEREST}

The author declares no conflict of interest, financial or otherwise.

\section{ACKNOWLEDGEMENTS}

This study was financially supported by Seoul National University of Science \& Technology.

\section{REFERENCES}

[1] G. Altshuller, The innovation algorithm: TRIZ, system innovation and technical greativity., GA Intervision, 2012.

[2] J. Zhao, G. Cai, H. Degee, Bo. Huang, and Z. Luo, "Hydration, Setting and Crack-Resistance Properties of Activated HAFACs at Early Stages", Appli. SCi, vol. 6, no. 8, p. 224, 2016. [http://dx.doi.org/10.3390/app6080224]

[3] R. Wang, and X. Gao, "Relationship between Flowability, Entrapped Air Content and Strength of UHPC Mixtures Containing Different Dosage of Steel Fiber", Appli. Sci., vol. 6, no. 8, p. 216, 2016.

[4] L. Monfardini, and F. Minelli, "Experimental Study on Full-Scale Beams Made by Reinforced Alkali Activated Concrete Undergoing Flexure", Materials, vol. 9, no. 9, p. 739, 2016

[http://dx.doi.org/10.3390/ma9090739]

[5] H.H. Kim, C.S. Kim, J.H. Jeon, and C.G. Park, "Effects on the Physical and Mechanical Properties of Porous Concrete for Plant Growth of Blast Furance Slag, Natural Jute Fiber, and Styrene Butadience Latex Using a Dry Mixing Manufacturing Process", Materials, vol. 9, no. 2, p. $84,2016$.

[http://dx.doi.org/10.3390/ma9020084]

[6] T. Kim, S. Tae, C. Chae, and K. Lee, "Proposal for the Evaluation of Eco-Efficient Concrete", Sustainabillity, vol. 8, no. 8, p. 705, 2016. [http://dx.doi.org/10.3390/su8080705]

[7] Kim. S.C., "Development of Fabrication Method for Translucent Concrete and the Material Characteristic Associated with the Use of Mineral Admixture", j. Korea Recycled Constr. Resour. Inst., vol. 6, no. 3, pp. 69-78, 2011.

[8] M.A. Munaaim, K.M. Al-Obaidi, M.R. Ismail, and A.M. Rahman, "Empirical Evlaution of the Effect of Heat Gain from Fiber Optic 
Daylighting System on Tropical Building Interiors", Sustainabillity, vol. 6, pp. 9231-9243, 2014.

[http://dx.doi.org/10.3390/su6129231]

[9] M.A. Munaaim, K.M. Al-Obaidi, M.R. Ismail, and A.M. Abdul Rahman, "A Review Study on the Application of the Fibre Optic Daylighting System in Malaysian Building", Int. J. sustainable Build. Technol. Urban Develop., vol. 5, pp. 1-13, 2014.

[10] I. Ullah, and S.Y. Shin, "Development of Optical Fiber-Based Daylight System with Uniform Illumination", Journal of Optical Society of Korea, vol. 16, pp. 247-255, 2012

[http://dx.doi.org/10.3807/JOSK.2012.16.3.247]

[11] Litacon Ltd. Available at: http://itracon.hu/en/products/litracon-blokk

[12] B. Kim, Development of Environmental Friendly Cement-Concrete Block and Application Technology", KICT, Goyang, Gyeonggi, Korea, KICT 2014-200 Report, 2004.

\section{C) 2017 Byoungil Kim.}

This is an open access article distributed under the terms of the Creative Commons Attribution 4.0 International Public License (CC-BY 4.0), a copy of which is available at: https://creativecommons.org/licenses/by/4.0/legalcode. This license permits unrestricted use, distribution, and reproduction in any medium, provided the original author and source are credited. 